\title{
CLINICAL ASPECTS OF SUSCEPTIBILITY TO METHYLPENTYNOL
}

\author{
BY \\ EDWARD MARLEY* and ALLEN A. BARTHOLOMEW \\ From the Bethlem Royal and Maudsley Hospitals, London
}

Methylpentynol (" oblivon "), one of the vinylethynl carbinols, was introduced into therapeutics by Margolin, Perlman, Villani, and McGavack (1951). Sears (1956) describes it as an important sedative producing mental relaxation and diminution of anxiety. The interest of the substance resides in the fact that not only is it an alcohol used therapeutically, but it is said to behave dissimilarly to the lower alcohols in that it is rapidly metabolized and is not cumulative in effect (Perlman and Johnson, 1952). The clinical evidence presented here argues against this and accumulation in animals has now been demonstrated by Marley and Vane (1958).

Preliminary investigations suggested that methylpentynol was less noxious than the barbiturates, a supposition modified by Goodman and Gilman (1955) who considered it more potent for man than for animals. Even so, early reports were unanimous in emphasizing the drug's paucity of toxic complications (Allen and Krongold, 1951; Hirsh and Orsinger, 1952; Malone, Klimkiewicz, and Gribetz, 1952) and human subjects have received $0 \cdot 1$ to $1 \cdot 5 \mathrm{~g}$. daily for six months without presenting undesirable side-effects (Chevalley, Heminway, Meyer, Frankhauser, and McGavack, 1952).

Recently, however, a number of dissentient publications have drawn attention to the drug's potential toxicity. Schaffarzick and Brown (1952) reported that two of six epileptics prescribed the substance developed a positive cephalin flocculation test. May and Ebaugh (1953) noted drowsiness, ataxia, and slurred speech in five patients who had ingested between 3.89 and $10.16 \mathrm{~g}$. of methylpentynol during periods from two to six days. Glatt (1955) and Marley (1955) reported toxic sequelae from abuse of the drug, while Lovelace and Roith (1955) documented an attempted suicide with a combination of methylpentynol and " persomnia" (carbromal and bromvaletone). A death after a dose of 4.5 to $6.0 \mathrm{~g}$. was confirmed by Cares, Newman, and

* Present address: Department of Pharmacology, Royal College of Surgeons, Queen Square, London
Mauceri (1953) and another following the absorption of $2.25 \mathrm{~g}$. of methylpentynol with 20 pentobarbitone sodium (" nembutal") capsules (British Medical Journal, 1955).

Marley and Chambers (1956) were struck by the similarity between alcohol, barbiturate, and methylpentynol intoxications, and by the apparently small precipitating dose of the latter substance. While much information is available relating to the therapeutic applications of the drug (Bockner, 1957; Bourne, 1954; Gusterson, 1955; Simmons, 1954; Simpson, 1954; Trotter, 1953), little is known as to its limitations or contraindications, although Lasagna (1954) noted that its hypnotic effect (0.5 to $1 \mathrm{~g}$. doses) was indistinguishable from placebo. A maximum of $2 \mathrm{~g}$. a day has been suggested for sedation, although this might now seem too high. Sargant (1956) has justifiably inveighed against the prescription of a standard dose irrespective of the circumstances, for this ignores the inherent individual variability that influences the parameter of drug dosage and response.

Such a topic is far from banal, and medico-legal implications in connexion with an abnormal response to methylpentynol have been discussed elsewhere (Lancet, 1955). It was therefore deemed worth while to ascertain more exactly the clinical response to methylpentynol as distinct from its purely therapeutic effect.

\section{METHODS}

Fifty-four individuals ( 24 males, 30 females) aged 18 to 60 years were prescribed $0.5 \mathrm{~g}$. q.d.s. of methylpentynol daily for five days, a base line of individual rea tion being obtained by the immediate prior administration for the same period of an identical number of inert capsules. The subjects were informed that they would receive a drug from which they might or might not derive benefit and that each would be interviewed daily. Neither they nor the nursing staff were aware that inert capsules were being prescribed. An electro-encephalogram was obtained on the fifth day of the course of inert capsules (control E.E.G.) and again on the final day of the drug régime (drug E.E.G.). Of the 54 subjects, 18 were normal volunteers, and the remainder were in hospital 
with psychiatric disorders presenting anxiety or tension (neuroses or psychosomatic illnesses). Patients with factors likely to modify the response to drugs, such as a history of drug addiction, head injury, or hepatic or renal impairment, were excluded from the series.

The particular dose of methylpentynol chosen is the maximum recommended for sedation, and the five-day period of study was selected as it was anticipated to be too brief for either accumulation of the drug or for exposing anything but maximum susceptibility to the substance. The clinical response to methylpentynol was graded into three categories, the unexpected and considerable incidence of toxic phenomena determining a classification. Depending on the presence or absence of abnormal signs in the central nervous system, the categories were designated none, minimal, and maximal toxic. In a few individuals there were marked behavioural changes without abnormal signs, apparently attributable to a toxic effect of the drug. The clinical rating in these subjects depended on the degree of disturbance seen in the electro-encephalogram. (Our use of the word "toxic" requires amplification, inasmuch as it has been applied to undesirable side-effects produced by the drug. Robson and Keele (1951) refer to two main types of toxic effect arising during the administration of drugs. These are those ascribable to overdosage or to either idiosyncrasy or hypersensitivity. In our series, the toxic response was probably due to a combination of individual hypersensitivity with overdosage, $2 \mathrm{~g}$. a day being too high for universal administration.)

The prototypes of clinical response to methylpentynol are as follows:-

A maximal toxic reaction (clinical grading 3) included most of the following:-Dilated pupils reacting sluggishly to stimuli, suffusion of the conjunctivae, sustained nystagmus on conjugate lateral gaze, diminished corneal reflexes, diplopia, ptosis, loss of tone in the lower facial musculature, dysarthria, and fine tremor of the protruded tongue. Cerebellar ataxia might be found in the limbs or an admixture of this with posterior column type of ataxy. The specific cerebellar features included intention tremor, dysdiadokokinesis, and dysmetria. Muscular hypotonia with diminished deep reflexes was also noted. Alteration in the mental state included distortion of mood, behaviour anomalies, impairment of attention, concentration, and abstract thought.

A minimal toxic reaction (clinical grading 2) was epitomized by little more than nystagmus on conjugate lateral gaze and slight unsteadiness of gait or drowsiness. Alterations of mood were also evident.

The designation of no toxicity (clinical grading 1) is self explanatory.

The presentation of the mental state is based on the method of examination used at the Maudsley Hospital. Bonnier's (1905) classification for body-image disturbance was used as was Lewis's definition of insight, that of a correct attitude to a morbid change in oneself (Lewis, 1934). As far as possible, the information relating to the mental status was quantified (Tables I-VII). In two of these (Tables V and VII) the significance of the results was determined by $t$ tests for correlated data, while for another three (Tables III, V and VI) the results were assessed by an arc sine transformation, which is a statistical technique for analysis of small populations (Davies, 1954). In order that the transformations should be valid the raw data were rearranged into $2 \times 2$ con- $\underset{\complement}{\complement}$ tingency tables achieved by contrasting the proportion $\bar{O} \rightarrow$ of individuals affected and not affected for the particular function under investigation, e.g., mood change, im- $\frac{8}{0} \underset{2}{\stackrel{0}{~}}$ pairment of retrospective memory, or subjective time alteration, falling into either clinical grading 1 or the 흑 임 combined clinical gradings 2 and 3.
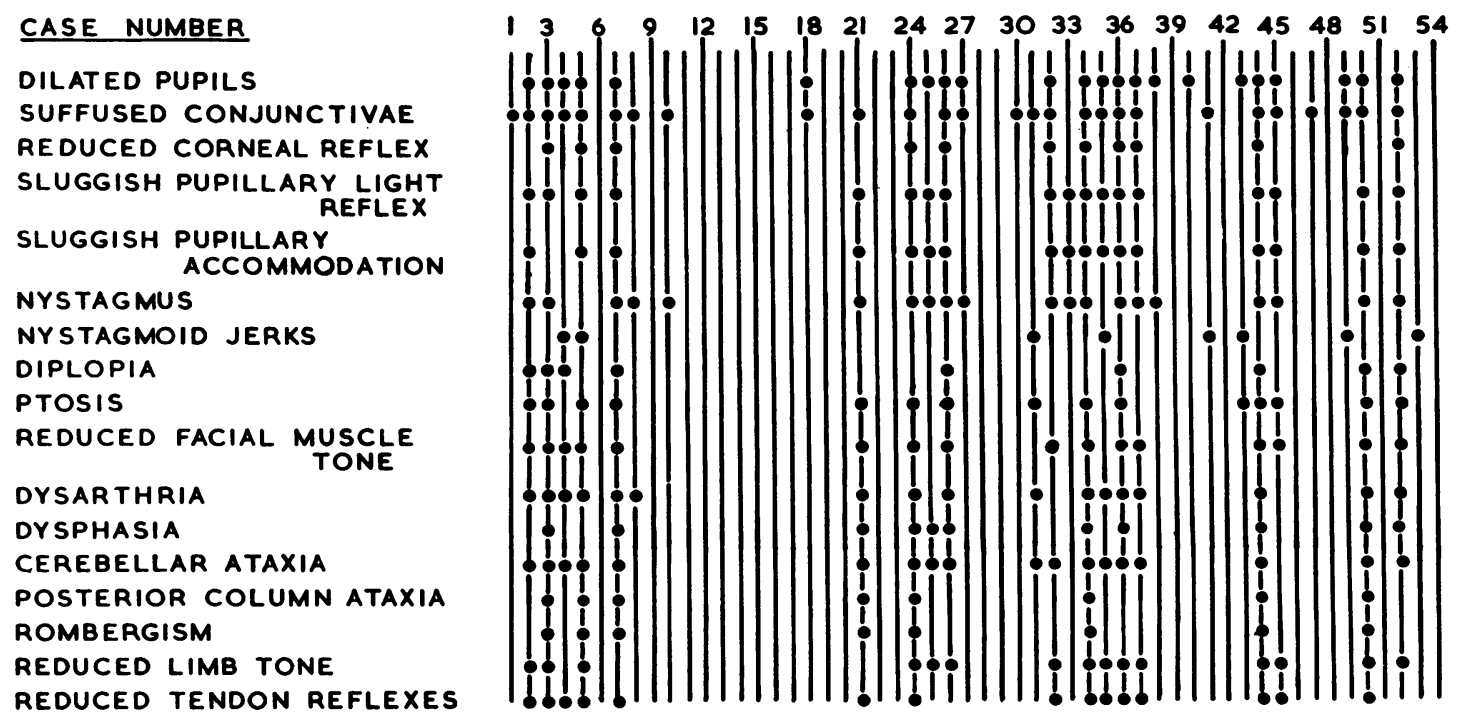

FIG. 1.-Abnormal physical signs seen in subjects given methylpentynol $0.5 \mathrm{~g}$. q.d.s., for five days. 


\section{RESULTS}

Of the 54 patients, 22 showed no reaction to methylpentynol, 15 developed minimal and 17 maximal toxic reactions. The abnormal physical signs encountered in patients manifesting susceptibility are depicted in Fig. 1.

\section{Abnormal Physical Signs}

Ocular Disorders.-Marked suffusion of the conjunctivae was noted in 27 subjects.

Alterations in pupil size were discovered in 23 patients, amounting to unequal pupillary dilatation in one (Case 52) and equal bilateral dilatation of the pupils in the 22 other affected individuals. These abnormalities were grouped with a spectrum of other physical changes except in two subjects (Cases 18, 40).

The light reflex was sluggish to both direct and consensual stimulation in 18 subjects, while that for reflex accommodation was impaired in 17.

The corneal reflex was reduced in 11 of the series, but only when accompanied by reduction of facial muscle tone (Cases 3, 5, 7, 24, 26, 32, 34, 36, 37, $44,52)$ and in association with bilateral ptosis in ail except two of the cases (Cases 32, 37).

In spite of the absence of paralytic strabismus or of any apparent disturbance of reflex conjugate lateral or vertical gaze, erroneous projection of the visual field was noted in nine patients. The diplopia was unilaterally or bilaterally uncrossed on lateral gaze for seven of the affected individuals and crossed for two others (Cases 26, 36). Diplopia on vertical gaze was seen in Case 52 only.

Sustained horizontal nystagmus on conjugate lateral deviation of the eyes was noted in 20 patients and unsustained nystagmoid jerks in a further eight individuals. Occasionally a small rotatory element to the nystagmus was evident.

Facial Musculature Tone.-Ptosis of the upper eyelids was seen in 15 subjects, together with, in 13 of these, a symmetrical loss of tone of the lower face musculature (Fig. 2). The ptosis might be unilateral or bilateral and was associated with overaction of the frontalis muscle. The drooping of the lid was slight, suggesting involvement of the orbital smooth muscle, but conjugate vertical elevation of the eyes was usually, although not invariably, unaccompanied by elevation of the upper lids. No actual weakness of the facial musculature was discovered.

Speech Disorders.-Seventeen patients became dysarthric while receiving methylpentynol. Mixed varieties of dysphasia compatible with a general disturbance of central nervous function was encountered in 11 individuals. This amounted in the

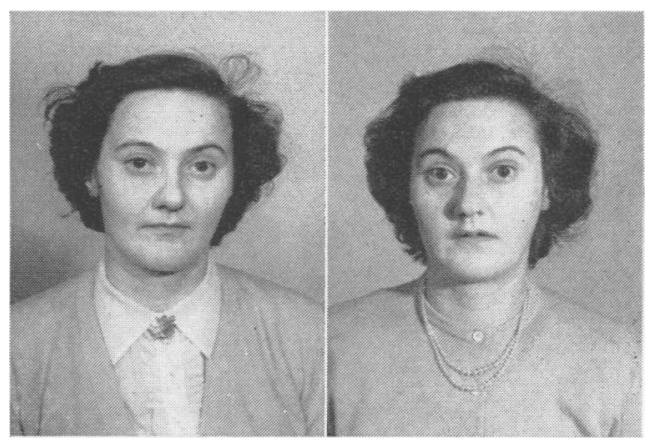

(A)

(B)

FIG. 2.-Loss of lower facial musculature tone in a subject with methylpentynol intoxication:

(A) Control, (B) Receiving drug.

mildest form to nominal dysphasia with the patient failing to name unfamiliar objects and without resort to periphrasis. In more severe instances, dysprosody, paragrammatism, and even paraphasia developed (Cases 3, 21, 32). Comprehension of spoken speech was normal, and no dyspraxic or gnostic difficulties emerged.

Tremor of the tongue was fine and rapid in character being elicited on protrusion of the tongue in 14 individuals (Cases 2, 4, 5, 21, 24, 26, 32, 34-36, $44,49,50,52$ ).

Trunk and Limbs.-Static tremor of the outstretched hands was found in 10 patients (Cases 2, $4,5,21,31,34,44,49,50,52$ ).

No gross abnormality of the rapidity, strength, or range of active movements was encountered. Coordination was affected, and, of the 18 individuals becoming ataxic, 10 exhibited cerebellar features in pure culture (Cases 2, 4, 25, 26, 31, 32, 35-37, 52) and eight presented a picture of mixed cerebellar and posterior column ataxy. Of the specific abnormalities, intention tremor on the finger-nose and heel-toe tests not compensated for by vision and dysmetria was commonest. Dysdiadokokinesis was also seen. These disturbances occurred in the presence of other abnormalities, nystagmus or nystagmoid jerks being invariably present. Reduced limb tone was found in $\mathbf{1 5}$ of the patients.

A number of subjects complained of unsteadiness in the absence of any substantiating deficit. In severely affected cases, the abnormality of gait was obvious, the Romberg test being positive in eight such patients.

The deep reflexes were diminished in 15 subjects.

\section{Mental State}

The diagrammatic representation of the mental state (Fig. 3) has entailed simplification, and modalities unaffected by the drug, e.g., orientation, have been omitted. 
CASE NUMBER

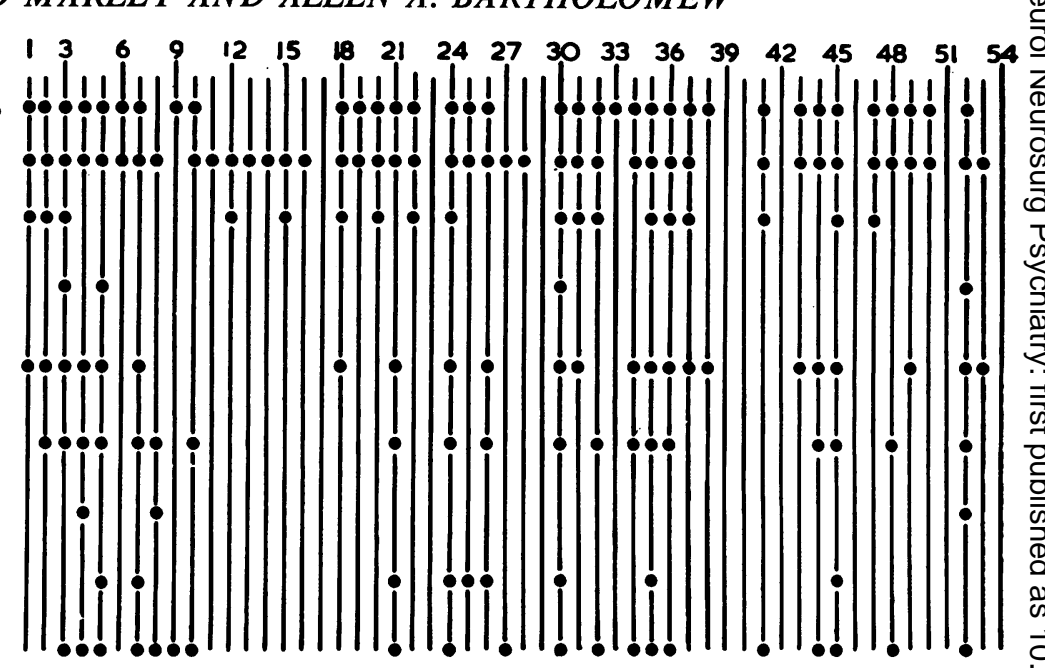

BEHAVIOURAL ABNORMALITIES

MOOD CHANGES

ABNORMALITIES OF TALK

ILLUSIONS OR

HALLUCINATIONS

IMPAIRED ATTENTION AND CONCENTRATION

IMPAIRED RETROSPECTIVE
MEMORY

BODY IMAGE DISTURBANCE

DEPERSONALISATION DEREALIZATION

SUBJECTIVE TIME CHANGE

FIG. 3.-Abnormal mental phenomena in subjects given methylpentynol, $0 \cdot 5$ g. q.d.s., for five days.

General Behaviour.-This is exemplified in the four adjectival subdivisions, normal, drowsy, overactive, and aggressive, although no behavioural spectrum could be codified adequately in this restricted fashion. Details are presented in Table I.

TABLE I

DISTRIBUTION OF BEHAVIOUR PATTERNS RELATED TO CLINICAL RESPONSE TO METHYLPENTYNOL

\begin{tabular}{l|r|r|r}
\hline \multirow{2}{*}{ Behaviour } & \multicolumn{3}{|c}{ Clinical Grading } \\
\cline { 2 - 4 } & 1 & 2 & 3 \\
\hline Normal & 16 & 3 & 0 \\
Drowsy & 1 & 10 & 13 \\
Overactive & 3 & 0 & 2 \\
Aggressive & 2 & 2 & 2 \\
\hline
\end{tabular}

It can be seen that apparently normal behaviour predominates in those invididuals with the clinical grading 1 , whereas drowsiness is most frequent for those responding adversely to methylpentynol (clinical gradings 2 and 3 ). Overactivity or aggressive behaviour showed no correlation with the clinical categories. As behaviour stems so manifestly from its affective setting, the behavioural and affective components were grouped together (Table II) to determine whether any associations could be abstracted from the resulting matrix.

It is evident that apparently normal behaviour may occur with euphoria or mild elation and that drowsiness was almost invariably associated with change of mood, particularly depression. Motor overactivity appeared to be linked with the emergence of euphoria or elation. Aggressive behaviour might parade as a modification of attitude, for example, unusually brazen behaviour, lack of tact, or outspokenness, proceeding in one instance to an
TABLE II

\begin{tabular}{|c|c|c|c|c|}
\hline \multirow{2}{*}{$\begin{array}{l}\text { Behavioural } \\
\text { Component }\end{array}$} & \multicolumn{2}{|r|}{ AFFECTED } & \multicolumn{2}{|l|}{ COMPONENT } \\
\hline & Normal & $\begin{array}{l}\text { Depressed } \\
\text { Irritable }\end{array}$ & $\begin{array}{c}\text { Elated } \\
\text { Euphoric }\end{array}$ & $\begin{array}{c}\text { Other } \overparen{D} \\
\text { Change? }\end{array}$ \\
\hline $\begin{array}{l}\text { Normal } \\
\text { Drowsy } \\
\text { Overactive } \\
\text { Aggressive }\end{array}$ & $\begin{array}{l}9 \\
3 \\
0 \\
0\end{array}$ & $\begin{array}{r}1 \\
18 \\
0 \\
3\end{array}$ & $\begin{array}{l}8 \\
0 \\
5 \\
1\end{array}$ & $\begin{array}{l}\mathbf{1} \\
\mathbf{3} \\
\mathbf{0} \\
\mathbf{2}\end{array}$ \\
\hline
\end{tabular}

assault on a nurse (Case 30). It is relevant that this $\vec{c}$ person before receiving the drug had regularly resorted to paranoid mechanisms in his adaptive behaviour. Aggressive reactions were encountered in six subjects (Cases 18, 21, 22, 30, 47, 50). Other behavioural alterations related to appetite, euphoric or elated individuals showing improvement, while those with depression suffered a decline in function.

Affective Changes.-These fell approximately into the triad of no alteration, elation or euphoria, and depression combined with irritability.

Table III sets out the relation of change of mood to the presence or absence of toxic phenomena. It is evident that the absence of mood changes or the development of elation or euphoria is likely to be associated with a grading of no toxicity, while the emergence of depression and irritability is linked with ratings of minimal or maximal toxicity.

The significance of the data was assessed using an arc sine transformation. It was found that the proportion showing affective changes (30 out of 32 subjects) was significantly greater among individuals responding adversely to methylpentynol, than the proportion with mood alterations but without toxic features (12 from 22 subjects), the critical 
TABLE III

RELATION OF MOOD TO CLINICAL RESPONSE TO METHYLPENTYNOL

\begin{tabular}{l|r|r|r}
\hline \multicolumn{1}{c|}{ Mood } & \multicolumn{3}{|c|}{ Clinical Grading } \\
\cline { 2 - 4 } & 1 & 2 & 3 \\
\hline Unaltered & 10 & 2 & 0 \\
Elated, euphoric & 9 & 3 & 2 \\
Depressed, irritable & 2 & 8 & 13 \\
Other mood change & 1 & 2 & 2 \\
\hline
\end{tabular}

ratio being $3.46(\mathrm{P}<0.01)$. However, euphoria or elation might occur in the absence of other changes attributable to the drug, and of the 14 affected individuals (Cases 3, 6, 12-14, 16, 19, 20, 27, 28, $44,47,48,53)$ only three were found to have impaired concentration and attention (Cases 3, 44, 53). On the other hand, not only was depression likely to be associated with toxic signs, but its emergence was an almost constant portent of the incipient toxic episode. Irritability came usually to blend with depression, but with negligible tension and without agitation. Perplexity when present was so intermingled with impairment of attention and concentration as to make attempts to place in separate categories artificial. The somatic accompaniments of depression were shown, particularly loss of appetite and motor drive.

Of the six patients who showed aggressive features, in three this canalized from a setting of impaired attention and concentration (Cases 18, 21, 30). All six were manifestly irritable, but only one was depressed (Case 50). Affective qualities, such as ambivalence, inadequate or inappropriate mood, were not seen.

Mood alterations were reversible, usually disappearing within three or four days of withdrawing the drug, but persisting in one patient for three weeks (Case 5).

Talk.-Thought and its consort, conversation, are considered together, abnormalities of either being cited under unified headings relative to production, progression, and content. The two extremes of talk are represented by "uncommunicative" and "garrulous". Nine patients were described as uncommunicative, this being an unusual attribute of their personality. One was without toxic signs
(Case 15), two exhibited minimal toxic changes (Cases 1, 45), while six developed marked toxic signs (Cases 2, 31, 32, 35-37). Garrulity is recorded for nine individuals, four of whom were otherwise unaffected by methylpentynol (Cases 12, 20, 22, 47), three displayed mild toxic phenomena (Cases 18, 30,41 ), and two severe toxic changes (Cases 3, 24). Train of thought was facilitated in patients with elation or euphoria, while depressed subjects experienced difficulty in thinking.

Thought content was usually appropriate to the mood change. Thus one depressed individual remarked, "I'm a failure. I'd like to be dead. Will the tablets kill me if I take enough ?" (Case 52). In contrast, a mildly elated patient (Case 6) asserted, "I feel much better . . . in fact, on top of the world. This is the best I've been for years."

Remarks such as these suggest that a patient may judge the efficacy of a drug not by its effect on symptoms, but rather by its capacity to boost mood, and hence modify his attitude towards symptoms.

\section{Digit Span}

The mean score and standard deviations for performance on digits forwards and backwards during both a control period and while on the drug was recorded for 49 of the 54 patients. As with the serial sevens test, a control score was determined for approximately half the subjects ( 24 patients) during the time they were receiving inert capsules, and for the remaining 25 subjects after a lapse of at least a week following withdrawal of methylpentynol. The data are presented in Table IV.

For patients showing no toxic developments, the mean digit score was virtually identical and without significant difference for both control and drug periods. Patients who responded badly to methylpentynol showed a falling off in digit retention. As might be expected, those individuals with maximal toxic developments (clinical grading 3) fared least well, the differences between mean scores for control and drug phases being highly significant for both digits forwards $(t=5.82, \mathrm{P}<0.001)$ and digits backwards $(t=4.76, P<0.001)$. Those subjects with minimal toxic developments (clinical grading 2) suffered a smaller decline in performance ascribable

TABLE IV

MEAN DIGIT RETENTION SCORES AND STANDARD DEVIATIONS DURING ADMINISTRATION OF INERT CAPSULES AND METHYLPENTYNOL

\begin{tabular}{|c|c|c|c|c|c|}
\hline \multirow{2}{*}{$\begin{array}{l}\text { Clinical } \\
\text { Grading }\end{array}$} & \multirow[b]{2}{*}{$\mathbf{N}$} & \multicolumn{2}{|c|}{ Digits Forward } & \multicolumn{2}{|c|}{ Digits Backward } \\
\hline & & $\begin{array}{c}\text { Control } \\
\text { (Inert Capsule) }\end{array}$ & $\underset{\text { (Methylpentynol) }}{\text { Drug }}$ & $\begin{array}{c}\text { Control } \\
\text { (Inert Capsule) }\end{array}$ & $\underset{\text { (Methylpentynol) }}{\text { Drug }}$ \\
\hline $\begin{array}{l}1 \\
2 \\
3\end{array}$ & $\begin{array}{l}22 \\
13 \\
14\end{array}$ & $\begin{array}{l}6.54 \pm 0.97 \\
6.00 \pm 0.88 \\
6.78 \pm 1 \cdot 12\end{array}$ & $\begin{array}{l}6 \cdot 27 \pm 0.88 \\
5.46 \pm 1.01 \\
5 \cdot 21 \pm 2.22\end{array}$ & $\begin{array}{l}4.45 \pm 0.82 \\
4.53 \pm 0.88 \\
5.07 \pm 0.72\end{array}$ & $\begin{array}{l}4.45 \pm 0.82 \\
3.77 \pm 0.69 \\
4.07 \pm 1.22\end{array}$ \\
\hline
\end{tabular}


to the drug; for digits forwards $t=2.01, \mathrm{P}<0.05$ and for digits backwards $t=2.97, \mathrm{P}<0.01$.

\section{Retrospective Memory}

By retrospective memory is meant recollection for that period during which methylpentynol was administered. A designation of moderate impairment of retrospective memory applied when an individual was discovered to have partial amnesia for events during the prescribed interval, and severe impairment of retrospective memory when he was able to give at most a meagre account of events during this time. These ratings were allotted after an interview with the patient at least two weeks after withdrawal of the drug. Details are included in Table V.

TABLE V

DISTURBANCE OF RETROSPECTIVE MEMORY AFTER METHYLPENTYNOL

\begin{tabular}{l|r|r|r}
\hline \multirow{2}{*}{ Retrospective Memory } & \multicolumn{3}{|c}{ Clinical Grading } \\
\cline { 2 - 4 } & 1 & 2 & 3 \\
\hline Unaffected & 21 & 11 & 3 \\
Moderate impairment & 1 & 2 & 9 \\
Severe impairment & 0 & 2 & 5 \\
\hline
\end{tabular}

The significance of the data was assessed with an arc sine transformation. A significant difference was found between the proportion with memory impairment in the groups evincing no susceptibility to methylpentynol (one subject out of 22) as compared with the proportion with memory impairment and responding adversely to the drug (18 from 32 patients), the critical ratio being $4.69(\mathrm{P}<0.001)$. The inference that memory impairment is much more likely in patients who developed toxic manifestations is thus amply substantiated.

These findings are of interest, inasmuch as impairment of retrospective memory developed in the absence of disorientation and can only be associated with the impairment of attention and concentration in those individuals responding adversely to the drug; even so, no defect for registration of present events had been noted. No relation was apparent between increasing age and liability to memory impairment, for of the 19 affected individuals only four were over the age of 40 years (Cases 10, 24, 30, 44).

\section{Illusions and Hallucinations}

Four instances were encountered, one in a patient with a minimal toxic rating (Case 30) and the other three in subjects with a maximal rating (Cases 3, $5,52)$.

The first (Case 3) was that of a man who observed a face on the ceiling, allegedly that of his mother, and heard the muttering of voices. The disturbances occurred on the fourth night of receiving methylpentynol. The patient was an immature person and very attached to his mother. Another patient (Case 5) on the fifth night of the drug insisted she had seen a woman, probably her mother, standing over her bed. The illusion or hallucination occurred only once and the patient realized that it was an unreal phenomenon. This subject was also abnormally dependent on her mother. In the third instance (Case 30) the patient during the third evening of receiving methylpentynol misinterpreted a shadow for a dog and then complained of itching of the skin. These abnormalities recurred each night until the drug was withdrawn. The final patient (Case 52) insisted during the last evening on the drug that his room was full of animals.

In summary, the disturbances, predominantly visual but also aural and perhaps tactile, occurred during the evening. They were fleeting in nature, were recognized as insubstantial and did not provoke an unpleasant affective response. They embodied material occurring normally in the patient's lives, and for at least two of them this was of specific emotional importance.

\section{Body Image}

Many morbid states are lent piquancy by altera- $\frac{\overline{\mathbb{D}}}{2}$ tions in body image, the changes ranging fromo enhancement to diminution or distortion. In spite of the straightforward categories of Bonnier (1905) descriptive overlap occurred.

Hyperschematia.-One instance was encountered although it could readily be incorporated under paraschematia. The patient (Case 8) complained of a feeling of enlargement of his head and the upper trunk. "My head and face seem swollen, even down to the waist. My hands and arms feel small."

Other individuals complained of "heaviness of the legs" but in all cases the experience seemed unimportant, meriting only incidental allusion.

Hyposchematia.-Some individuals noted "a feeling of lightness of the body or limbs ", but as above, the experiences never brooked large in the symptomatology.

Paraschematia.-Two examples were encountered (Cases 4, 52). One patient remarked "I seem to be two different people. When I brush my hair I feel I do it for someone else." The other related, "I don't seem myself. I don't recognize myself in my name. Nothing belongs to me. It's as if I was outside myself." The experiences of these two patients are reminiscent of what Lhermitte (1939) termed "bipartition of the postural schema and akin to the phenomenon of depersonalization". 
Depersonalization and Derealization.-Four examples of depersonalization were recorded (Cases 5, 21, 24, 45). Thus (Case 24): “ Everything is altered. My face feels numb and there is no feeling in my teeth. There is no life in my fingers. I just feel cold and dead." There were two instances of derealization (Cases 7, 35). The first (Case 7) remarked: "I feel as if I was miles away. It's a strange impression. The whole world seems distant." Three patients exhibited a mixture of depersonalization and derealization (Cases 25, 26, 30).

Schilder asserts that depersonalization and derealization are almost constantly accompanied by dizziness. This was true for all the affected individuals, but more specifically of the 12 subjects considered above; all but one (Case 30 ) showed nystagmus or nystagmoid jerks, and all but three (Cases 8, 30, 45) being ataxic.

Alteration in the appreciation of space may be supposed to be implicit in derealization, particularly in expressions relating to the remoteness or distance of the world (Case 7). Such remarks should be interpreted as symbolic expressions of an altered attitude to the outside world rather than true referents to physical space.

\section{Subjective Time Experience}

Whereas patients with body image disturbances could be relied on to voice them spontaneously, this was not true for alterations in time experience, evidence for which was only elicited by questioning. Of the 54 individuals, one patient refused information (Case 18), 33 noted no change, 13 stated time seemed to pass more swiftly, while seven insisted that its passage was slower, an extreme example of which is noted (Case 52): "Nothing is happening at all. Everything's slowed down and stopped." Details are included in Table VI.

The significance of the data was assessed using an arc sine transformation. A significant difference was noted between the proportion of subjects with alteration of time experience in the group responding normally to methylpentynol (20 (Table VI) out of 22 patients) as compared with the proportion evincing alteration of subjective time ( 18 from 31 subjects) and reacting adversely to the drug, the critical ratio
TABLE VI

SUBJECTIVE TIME EXPERIENCE AND CLINICAL RESPONSE TO METHYLPENTYNOL

\begin{tabular}{l|r|r|r}
\hline \multirow{2}{*}{ Subjective Time Experience } & \multicolumn{2}{|c}{ Clinical Grading } \\
\cline { 2 - 4 } & 1 & 2 & 3 \\
\hline Unaffected & 20 & 7 & 6 \\
Faster & 2 & 4 & 7 \\
Slower & 0 & 3 & 4 \\
\hline
\end{tabular}

being 4.06 ( $\mathrm{P}<0.001)$. Patients developing toxic phenomena with methylpentynol are therefore more disposed to distortion of subjective time experience than those individuals who respond normally to the drug.

\section{Orientation}

No subject developed disorientation for time, person, or place while receiving methylpentynol.

\section{Results of Serial Sevens Test}

The mean scores and standard deviations for the serial sevens test are depicted in Table VII.

In deference to experimental rigour, the control scores for half the subjects were obtained during the control period before the five-day course of methylpentynol, and for the other half after a lapse of at least one week after withdrawal of the drug. The results were scored both for the number of mistakes, " error score", with a maximum of 14 mistakes, and for the time taken in seconds to complete the test, time score. However, six individuals were unable to attempt the test after five days of methylpentynol (Cases 7, 18, 21, 24, 26, 30). Of these, two (Cases 18, 30) were minimally toxic, and the rest displayed maximal toxic features. An arbitrary score was obtained for these six subjects by allotting them the mean score derived from the remaining 48 individuals, plus an increment of thrice the standard deviation of the mean score.

The difference between control and drug mean scores for patients in clinical category 1 is not significant. For patients with minimal toxic changes (clinical grading 2) the difference between control and drug mean error scores is not significant $(t=1.93, \mathrm{P}>0.5)$, although the mean time required to complete the test while the drug is being administered is significantly increased $(t=4 \cdot 37$,

TABLE VII

MEAN ERROR AND TIME SCORES WITH STANDARD DEVIATIONS FOR SERIAL SEVENS TEST DURING ADMINISTRATION OF INERT CAPSULES AND METHYLPENTYNOL

\begin{tabular}{|c|c|c|c|c|c|}
\hline \multirow{2}{*}{$\begin{array}{l}\text { Clinical } \\
\text { Grading }\end{array}$} & \multirow[b]{2}{*}{$\mathbf{N}$} & \multicolumn{2}{|c|}{ Error Score (1-14) } & \multicolumn{2}{|c|}{ Time Score (sec.) } \\
\hline & & $\begin{array}{c}\text { Control } \\
\text { (Inert Capsules) }\end{array}$ & $\underset{\text { (Methylpentynol) }}{\text { Drug }}$ & $\begin{array}{c}\text { Control } \\
\text { (Inert Capsules) }\end{array}$ & $\begin{array}{c}\text { Drug } \\
\text { (Methylpentynol) }\end{array}$ \\
\hline $\begin{array}{l}1 \\
2 \\
3\end{array}$ & $\begin{array}{l}22 \\
15 \\
17\end{array}$ & $\begin{array}{l}0.59 \pm 0.98 \\
1.29 \pm 1.02 \\
0.59 \pm 1.08\end{array}$ & $\begin{array}{l}0.77 \pm 1.20 \\
2.00 \pm 1.41 \\
3.41 \pm 1.54\end{array}$ & $\begin{array}{l}47 \cdot 14 \pm 14 \cdot 06 \\
46 \cdot 07 \pm 11 \cdot 71 \\
53 \cdot 53 \pm 14 \cdot 80\end{array}$ & $\begin{array}{l}48 \cdot 05 \pm 20 \cdot 43 \\
70 \cdot 22 \pm 23 \cdot 74 \\
84.65 \pm 43.08\end{array}$ \\
\hline
\end{tabular}


P $<0.001)$. For subjects who developed a maximal toxic picture, the difference between control and drug mean error scores is significantly augmented $(t=3.37, \mathrm{P}<0.001)$ as is the mean time required for test performance $(t=2.82, \mathrm{P}<0.01)$.

These results indicate that in the minimal toxic categories accuracy at the serial sevens test is maintained at the expense of a longer period for completing the test, whereas in the maximal toxic categories inaccuracy at the test increases significantly in spite of the greater period devoted to test performance.

\section{Insight}

Insight was not impaired while individuals were receiving the drug, but those patients with impaired retrospective memory later experienced difficulty in recalling events and hence assumed logically correct albeit factually incorrect attitudes to the incident.

\section{Withdrawal Effects}

Three subjects (Cases 4, 32, 34) seemed worse after the drug was withdrawn, all experiencing nausea and complaining of feeling anxious or being cold and shivering. Vomiting unrelated to food was noted in Case 32. One of the patients (Case 34) became restless and paranoid 48 hours after stopping methylpentynol, misinterpreting shadows for people and objects in the ward as animals. This disturbance $\frac{}{2}$ subsided within two days.

\section{Electro-encephalograms}

The tracings (Fig. 4) came from a patient with maximal toxic features (Case 34). The anomalies 0 consist of 22 to 26 cycles-per-second activity of in creased voltage over the frontal and central regions? of the brain. These abnormalities were found regularly in subjects graded as maximally toxic, some also? showing slowing of the dominant post-central frequency. Minor electro-encephalographic altera- $\frac{-}{2}$ tions were noted in patients designated as minimally을 toxic, but not for individuals allocated to clinical $\overline{\frac{\sigma}{\sigma}}$. grading 1 . Three patients with marked behavioural ${ }_{\bar{\sigma}}^{\vec{\sigma}}$ changes, in the absence of abnormal signs following $\mathrm{\alpha}$ administration of methylpentynol, were rated asc clinically toxic on account of electro-encephalo- $\vec{\circ}$ graphic anomalies (Cases 18, 30, 47).

\section{Other Effects of Methylpentynol}

One instance of a generalized urticarial response to methylpentynol was seen (Case 38). This occurred on the third day of drug administration in a patient. with a history of asthma, hay fever, and urticaria.

\section{Urine}

The urine of patients developing toxic sigh
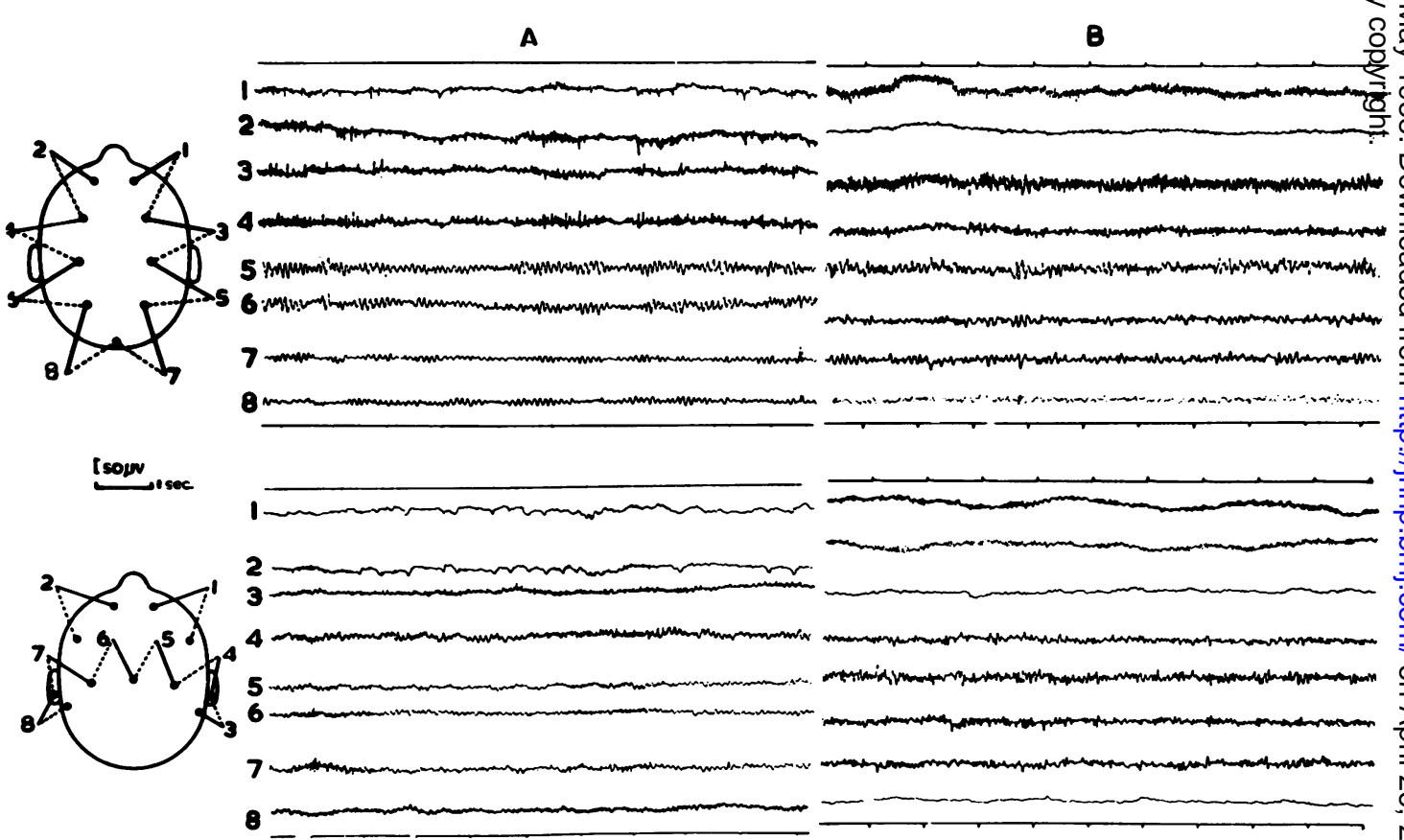

FIG. 4.-Control $(A)$ and abnormal $(B)$ electro-encephalograms from a subject with methylpentynol intoxication. Upper tracing, high sagittal $\omega$ electrodes; lower tracing, transverse central electrodes. Abnormal records reveal fast activity in the frontal and central areas. 
frequently contained a substance that reduced Benedict's solution, appearing first about the third day of the course of methylpentynol. Urinary frequency was also a common complaint.

\section{Placebo Effects}

None of the physical signs encountered with methylpentynol were seen when patients were receiving inert capsules, although there were alterations in the mental state, particularly changes of mood. These were noted in nine patients and consisted of the appearance of mild euphoria or depression. The affective changes had subsided in all but three (Cases $6,21,36$ ) by the time the active drug was prescribed. No body image disturbances were complained of but six individuals had depersonalization experiences (Cases 15, 18, 32, 41, $45,47)$. No other disturbances occurred although alteration of subjective time sense was not enquired for. There was a marked effect on symptomatology, and of the 34 patients in hospital, 10 stated they felt better while receiving inert capsules. The normal subjects noticed no change, as did the majority of the remaining patients, although four insisted there had been aggravation of their state.

There was thus a wide divergence between the effects of placebo and the active drug, so that correlations between the presence of abnormal symptoms and signs and the action of methylpentynol have a significant basis.

\section{Time Incidence of Toxic Phenomena}

Thirty-two patients responded adversely to methylpentynol. The distribution for the initial appearance of toxic signs shows peak frequencies on the third and fifth days of drug administration (Fig. 5). Only one instance of toxic response occurred before the third day.

\section{Susceptibility and Dosage}

It was conceivable that individuals developing toxic features with methylpentynol might remain free from complications if maintained on a reduced dose. Consequently, six subjects with pronounced susceptibility to methylpentynol were again prescribed the drug. Two were given $1 \mathrm{~g}$. a day. (Cases 21,34 ), two received $0.5 \mathrm{~g}$. daily (Cases 24,36 ), and two others $0 \cdot 25 \mathrm{~g}$. daily (Cases 26,35 ). None of the six manifested susceptibility although methylpentynol was given for 10 days. Similarly, three patients who were unaffected by the drug were prescribed doses in excess of the original régime (Cases $23,28,46$ ). Each received $2 \mathrm{~g}$. a day for five days, succeeded by $5 \mathrm{~g}$. daily for a further two days without the emergence of toxic phenomena.

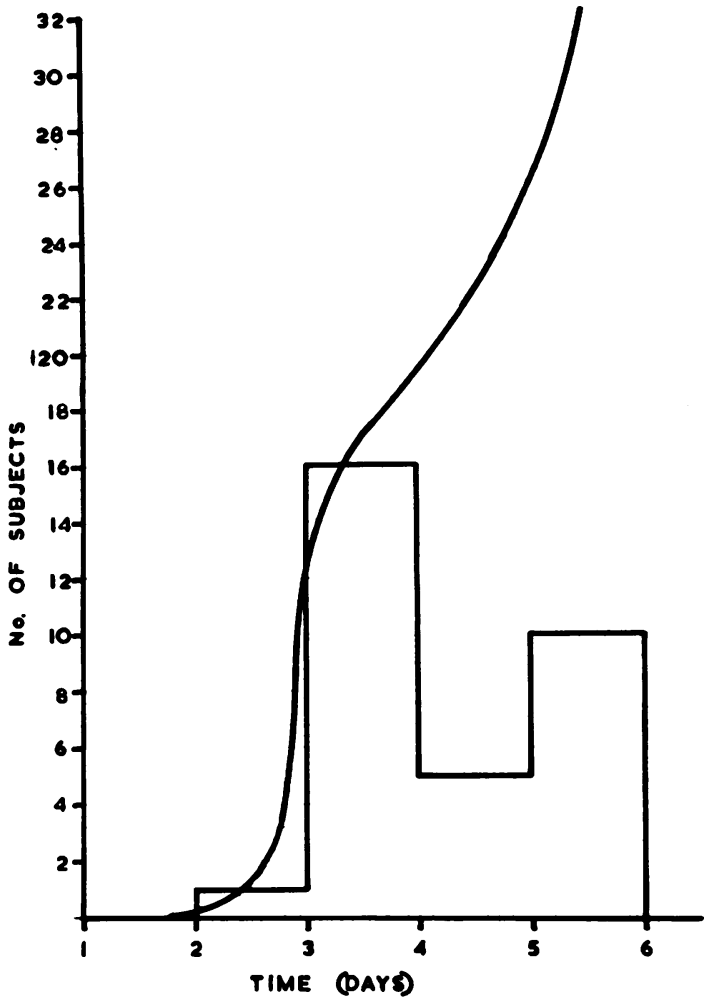

FIG. 5.-Histogram and integrated frequency curve for the initial appearance of toxic signs in 32 subjects responding adversely to methylpentynol.

\section{DISCUSSION}

The clinical picture of methylpentynol intoxication emulates that seen following the administration of many central nervous system depressants, there being a particularly telling resemblance to alcohol intoxication. Methylpentynol belongs to the series of higher alcohols, and these tertiary carbinols are known to produce depression of the central nervous system (Jenkins and Hartnung, 1943). As the activity of an alcohol increases with the size of its respective molecule (Gaddum, 1956) it is scarcely surprising that methylpentynol with its branched six-carbon chain should produce side-effects in a proportion of individuals.

Howells (1952) depicts the findings in 40 persons suspected of being under the influence of alcohol, including pupillary dilatation with impaired reaction to light or accommodation, suffused conjunctivae, nystagmus, and ataxia with a positive Romberg sign. Identical phenomena have been elicited in barbiturate poisoning, and Isbell and White (1953) have pointed to the similarity between alcohol and barbiturate intoxications. 
In our series, the presence of nystagmus on conjugate lateral deviation of the eyes as early as three days after beginning methylpentynol was a reliable indicator of a portending toxic reaction and confirms Howells' (1956) finding that nystagmus is the earliest eye sign produced by alcohol. Pupillary reflex abnormalities were found in only one-third of our group and consisted of impairment of the reaction to light and to accommodation, although dilatation of the pupils in the absence of any alteration of reflex response to stimuli was commoner still. Other anomalies included suffused conjunctivae, diminished corneal reflexes, diplopia, dysarthria, and fine tremor of the protruded tongue. In a quarter of the individuals, the lower facial masculature suffered a striking loss of tone accompanied by unilateral or bilateral ptosis.

Ataxia when present was of either cerebellar or posterior column variety or a mixture of the two. In consequence, limb muscle tone was usually diminished, although in one instance quoted by Hirst (1955) and in two patients seen by Marley and Chambers (1956) muscle tone was augmented and accompanied by sustained patellar and ankle clonus. Similarly, Isbell (1950) found that chronic barbiturate intoxication might present with ankle clonus and extensor plantar responses.

Paraphasia and nominal dysphasia were also encountered, being presumably an expression of general disturbance of central nervous function. Curran (1944), who believed that he could distinguish features specific to drug intoxications, stipulates that paraphasia is one of the hall marks of bromide deliria. There seems to be no logical grounds for assuming such symptomatological exclusiveness, and Mayer-Gross, Slater, and Roth (1954) allude to its occurrence in delirium tremens. Stengel and Mayer-Gross (1945) refer to paraphasic disturbances during recovery from hypoglycaemia. They noted, in deference to Paterson's criticism of a quantitative one-dimensional idea of consciousness (Paterson, 1944), that there were at least four levels of consciousness during hypoglycaemic arousal, paraphasia being associated with the least clouding of consciousness.

One of the other diverting facets of the action of methylpentynol was its ability to produce differential mood alterations, this effect being seen both in individuals manifesting toxic features and in those who did not. The spectrum of mood ranged from elation to depression, the development of a blend of depression and irritability being a constant harbinger of the emergence of neurological abnormalities. Ideational content remained congruous with the prevailing mood, to the extent even of suicidal ideas being expressed during a depressed period.
Euphoria and elation were usually noted in patients without toxic signs. Wikler (1952a) sug-D gested that in such circumstances euphoria or dysphoria were related each to the other in that both crystallized out when the sensorium was imso paired. We would concur with this finding for our series when depressive features were predominant but it was not the case when mood was heightened.

The eventual pattern produced by the drug seemed independent of the original pattern of mood for the subject, but all affective changes were rapidly reversible, usually abating within a few days of with-o drawing the substance. Alteration in motor activityo and appetite appeared subordinate to the particulare mood deviation. Mood changes in drug intoxication $\mathbb{\Omega}$ seem therefore of a non-specific character and have been so categorized by Thorner (1935), Cleghorn ${ }^{\infty}$ (1952), and Wikler (1952b). In spite of these. precedents, there is little allusion to the potential $\overrightarrow{{ }^{\prime}}$ adverse effect of the tranquillizing agents on mood. However, Dickel and Dixon (1957) have noted that individuals who should benefit from the drugso instead develop untoward reactions. Anxious people become depressed enough to commit suicide; eas - in going people become hypomanic or manic. It is o interest then that Curran (1944) witnessed appareat 0 hypomanic episodes in some cases of barbiturahe poisoning.

Disorientation has also been described as a toxic response to methylpentynol (Hollander, 1954. Levin (1951) formulated the entity of " partiolco delirium " which depended on the fact that orienta- $\infty$ tion for time, being an abstract concept, was more $\square$ vulnerable and consequently more likely to be upset than either orientation for place or for person. None of our patients exhibited disturbance of thiso modality, although attention, concentration, and $\overline{\mathbb{D}}$ abstract thought were impaired. Trotter (1954) found that speed of reaction, concentration, and응 coordination were either unimpaired or enhanced after $\mathbf{0 . 5} \mathrm{g}$. of methylpentynol, although Macdonald (1955), using $0 \cdot 25 \mathrm{~g}$. noted an $8 \%$ deterioration on numerical test. Kornetsky (1951) reported a decline in digit retention associated with the long-term? administration of barbiturates, while earlier stillo Hoch (1906) noted reduction of digit span with drug intoxications.

Visual illusions or possibly hallucinations oc- $₹$ curred infrequently, their content little more than projected material of current psychopathological $>$ import to the patient. For this reason they might be을. regarded as epiphenomena, although the personaln nature of such material is well-recognized. Noyes (1948a) remarks that not only are illusions likely to 0 be determined by the prevailing trend of the patient's $N$ preoccupations, but that the mental material which 
is externalized in the form of hallucinations is of a most intimate, subjective, and personal nature (Noyes, 1948b).

Recollection and recall are said usually to be good after confusional illnesses (Wolff and Curran, 1935) although mild to severe amnesia was the rule for patients who had developed pronounced toxic features. This might be considered surprising as orientation had remained intact. Bleuler (1951) suggested that disturbances of memory are the residue of diffuse interference with cerebral function, and to this the amnesia could be most sagaciously ascribed. Age is considered an important determinant in the development of amnesic syndromes, being the lot of the elderly rather than the young. We found no apparent correlation with age, presumably as the age range was circumscribed.

Disorders of body image were also apparent, the commonest being dizziness and sensations of lightness or heaviness either of the whole or of parts of the body. Feelings of unreality amounting to depersonalization or derealization were spontaneously mentioned. Schilder (1935a) has commented on the frequency of dizziness as an accompaniment to these experiential disorders. Certainly the majority of our patients so affected displayed abnormalities such as ataxia or nystagmus. Although one subject became depersonalized while receiving inert capsules, no patient admitted to a prior experience of a reminiscent quality, and there was no evidence in our series that reactions of this type constitute a preformed functional response as suggested by Mayer-Gross (1935).

A more specific disturbance of body image attributed to methylpentynol involved the head and upper part of the trunk, and Schilder (1935b) refers to the well-known experience of the head seeming larger after alcoholic intoxication. Such features are not confined to an aftermath of alcohol, and Critchley (1950) quotes Chapman as experiencing like phenomena while suffering from hunger and malaria (Chapman, 1949). The complaint of two other patients were akin to those that Lhermitte (1939) has dealt with under bipartition of the postural schema. All types of disturbance were classifiable into Bonnier's categories of hyper-, hypo-, and paraschematia, the best examples of which are usually seen in drug intoxications (Critchley, 1950).

Anomalies of subjective time experience occurred but could only be elicited by questioning. Time was said to pass more rapidly, or, less commonly, more slowly, the rate of passage of subjective time being apparently independent of the prevailing affective state although alteration of subjective time experience was found to be linked with an adverse response to methylpentynol. Hughlings Jackson (1932) suggested that this particular " prolongation " of time was the outcome of shallow dissolution of the highest centres and could be interpreted as a more rapid (or slower) succession of a time-constant peculiar to each individual. That anomalies of time experience should occur at all is hardly surprising for, as Lewis (1932) remarks, "It [abnormal time experience] is a primary alteration of consciousness and may be found almost as often as it is looked for in mental disorder."

Electro - encephalographic abnormalities were found at the height of intoxication and occasionally occurred with behavioural anomalies although in the absence of other toxic signs. The disturbance consisted of 22 to 26 cycles-per-second activity of increased voltage over the frontal and central regions of the brain. Although Tükel and Tükel (1952), who examined children sedated with 0.25 to $0.75 \mathrm{~g}$. of the substance, remarked that the records exhibited no features attributable to its action, Henry (1953) and Williams (1954) have drawn attention to minor alterations in the electro-encephalogram after the drug. This is theoretically to be anticipated, and the presence of 20 to 30 cycles-per-second wave activity in the frontal, and less often in the parietal, region has been noticed after administration of barbiturates (Brazier and Finesinger, 1945; Lennox, 1946). Cohn and Katzenelbogen (1942) suggest that this is not a specific barbiturate effect but may occur with cyclopropane anaesthesia and during the early stages of deep sleep.

Elaborate withdrawal symptoms after discontinuing the five-day régime of methylpentynol were evident in one instance. As noted by Isbell, Altschul, Kornetsky, Eisenman, Flanary, and Fraser (1950) for barbiturate addicts, anxiety, tremor, nausea, and insomnia appeared within 24 hours of stopping the drug, being succeeded by illusions and hallucinations after a lapse of three days. A small number of individuals developed nausea and even vomiting after ceasing methylpentynol but without the emergence of other symptomatology. The drug can therefore be fairly described as mildly habituating.

No skin reactions to methylpentynol as portrayed by DeLamater (1952) were encountered, although one patient with a history of allergic phenomena developed urticaria within three days of starting to take the drug.

The urine of patients developing toxic signs frequently contained a substance that reduced Benedict's solution. This was presumably due to the excretion in the urine of a breakdown product of methylpentynol conjugated with glycuronic acid, as has been shown to occur by Perlman, Sutter, and Johnson(1953). Complaints of urinary frequency were common when subjects were receiving the drug, and although no objective measurements of augmented 
fluid excretion were obtained, the diuretic action of alcohol is well authenticated (Eggleton, 1942).

As geometric increments or decrements of dose are related to arithmetic increase or decrease of drug response, it was presumed that subjects becoming toxic with $2 \mathrm{~g}$. daily of methylpentynol might remain free from adverse effects if the dose of the substance was reduced in geometric fashion. This assumption was found to hold good. Similarly, some patients manifested no ill effects from doses of methylpentynol well above the maximum recommended for sedation. Even so, it must be contended that for some individuals, methylpentynol accumulates in the body and that a dose of $2 \mathrm{~g}$. a day is not only excessive but well above the level that should be employed for long-term sedation.

\section{SUMMARY}

Fifty-four individuals were prescribed $0.5 \mathrm{~g}$. q.d.s. of methylpentynol for five days, preceded by a similar period on inert capsules.

Toxic effects appearing between the third and fifth day of the drug régime were seen in 32 subjects, all of whom recovered completely within four days of withdrawing methylpentynol.

The toxic phenomena included pupillary abnormalities, nystagmus, suffusion of the conjunctivae, ptosis, loss of facial muscle tone, dysarthria, tremor of the protruded tongue, and cerebellar ataxy in the limbs or admixtures of this with posterior column ataxia. Muscular tone was diminished as were the tendon reflexes. Electro-encephalographic abnormalities were encountered.

Mood change, particularly depression with irritability, dominated the accompanying mental state. Orientation was preserved even in a setting of impaired attention and concentration. Nominal dysphasia, paraphasia, and distortion of subjective time experience and body image were noted. Illusions or possibly hallucinations occurred, as did impairment of retrospective memory for the toxic episode. Prominent withdrawal features were seen in one instance.

It is contended that the drug accumulates in the body, and that a dose level of $2 \mathrm{~g}$. a day is too high for long-term sedation.

We take pleasure in thanking Dr. Denis Leigh for his kind permission to publish, Dr. A. E. Maxwell for invaluable statistical advice, and British Schering Ltd. for a generous supply of methylpentynol and inert capsules. We are indebted also to Mr. D. A. Green for preparation of the figures.

\section{REFERENCES}

Allen, A. W., and Krongold, D. D. (1951). Quart. Bull. Sea View Bleuler, Hosp., 12, 61.

Bleuler, M. (1951). Brit. med. J., 2, 1233.

Bockner, S. (1957). J Ment. Sci., 103, 218. 60.
Bourne, G. (1954). Lancet, 2, 522.

Brazier, M. A. B., and Finesinger, J. E. (1945). Arch. Neurol. Psychiat. (Chicago), 53, 51.

British Medical Journal (1955). 1, 296.

Cares, R. M., Newman, B., and Mauceri, J. C. (1953). Amer. J. clin. Path., 23, 129.

Chapman, F. S. (1949). The Jungle is Neutral. Chatto and Windus, London.

Chevalley, J., Heminway, N., Meyer, G., Frankhauser, R., and McGavack, T. H. (1952). N.Y.' St. J. Med., 52, 572.

Cleghorn, R. A. (1952). Amer. J. Psychiat., 108, 568.

Cohn, R., and Katzenelbogen, S. (1942). Proc. Soc. exp. Biol. (N.Y.), $49,560$.

Critchley, M. (1950). Lancet, 1, 335.

Curran, F. J. (1944). J. nerv. ment. Dis., 100, 142.

Davies, O. L. (1954). The Design and Analysis of Industrial Experiments, p. 26. Oliver and Boyd, London.

DeLamater, J. N. (1952). Calif. Med., 77, 339.

Dickel, H. A., and Dixon, H. H. (1957). J. Amer. med. Ass., 163, 422.

Eggleton, M. G. (1942). J. Physiol. (Lond.), 101, 172.

Gaddum, J. H. (1956). Lectures on the Scientific Basis of Medicine, vol. 4, 1954-55, p. 238. The Athlone Press. London.

Glatt, M. M. (1955). J. nerv. ment. Dis., 122, 390.

Goodman, L. S., and Gilman, A. (1955). The Pharmacological Basis of Therapeutics, 2nd ed., p. 169. Macmillan, New York.

Gusterson, F. R. (1955). Lancet, 1, 940.

Henry, C. E. (1953). Electroenceph. clin. Neurophysiol., 5, 321.

Hirsh, H. L., and Orsinger, W. H. (1952). Amer. Practic. Dig. Treatment (Philad.), 3, 23.

Hirst, G. (1955). Lancet, 2, 676.

Hoch, A. (1906). Rev. Neurol. Psychiat. (Edinburgh), 4, 83.

Hollander, W. M. (1954). J. Iowa St. med. Soc., 44, 257.

Howells, D. E. (1952). Brit, med. J., 2, 862.

Howells, D. E. (1952), Brit,

Isbell, H. (1950). Ann. intern. Med., 33, 108.

, Altschul, S., Kornetsky, C. H., Eisenman, A. J., Flanary, H. G., and Fraser, H. F. (1950). Arch. Neurol. Psychiat. (Chicago), 64, 1 .

Jack and White, W. M. (1953). Amer. J. Med., 14, 558.

Jackson, J. Hughlings (1932). Selected Writings of John Hughlings Jackson, vol. 2, p. 116. Hodder and Stoughton, London. Medicinal Products, 2nd ed., p. 69. Whe Chemistry of Or Wiley, New York.

Kornetsky, C. H. (1951). A.M.A. Arch. Neurol. Psychiat., 65, 557.

Lancet (1955). “Medicine and the Law", 2, 146.

Lasagna, L. (1954). J. Pharmacol., 111, 9. 999.

Levin, M. (1951). Ibid., 107, 689.

Lewis, A. (1932). Proc. roy. Soc. Med., 25, 611.

Lewis, A. (1932). Proc. roy. Soc. Med., 25,

Lhermitte, J. (1939). L'Image de Notre Corps. p. 47. Editions de la Nouvelle Revue Critique, Paris.

Lovelace, R. E., and Roith, A. I. (1955). Brit. med. J., 1, 1258.

Macdonald, A. D. (1955). Lancet, 1, 1265.

Malone, H. J., Klimkiewicz, G. R., and Gribetz, H. J. (1952). J. Pediat., 41, 153.

Margolin, S., Perlman, P., Villani, F., and McGavack, T. H. (1951). Science, 114, 384.

Marley E. (1955). Lancet, 2, 535.

, and Chambers, J. S. W. (1956). Brit. med. J., 2, 1467.

, and Vane, J. R. (1958)

May, P. R. A., and Ebaugh, F. G. (1953). Amer.J. Psychiat., 109, 881.

Mayer-Gross, W. (1935). Brit. J. med. Psychol., 15, 103.

Slater, E., and Roth, M. (1954). Clinical Psychiatry, p. 349. Cassell, London.

Noyes, A. P. (1948a). Modern Clinical Psychiatry, 3rd ed., p. 63. Saunders, Philadelphia.

(1948b). Ibid., $\mathrm{p}_{\text {. }} 65$.

Paterson, A. (1944). Proc. roy. Soc. Med., 37, 556.

Perlman, P. L. and Johnson, C. (1952). J. Amer. Pharm. Ass., sci. ed., 41, 13.

Sutter, D., and Johnson, C. (1953). Ibid. 42, 750 .

Robson, J. M., and Keele, C. A. (1951). Recent Advances in Pharmacology, p. 87. Churchill, London.

Sargant, W. (1956). Brit. med. J., 1, 939.

Schaffarzick, R. W., and Brown, B. J. (1952). Science, 116, 663

Schilder, P. (1935a). The Image and Appearance of the Human Body. Psyche Monog. No. 4, p. 140.

(1935b). Ibid., p. 96.

Sears, W. G. (1956). Practitioner, 176, 308.

Simmons, H. J. (1954). Brit. dent. J., 97, 21.

Simpson, R. G. (1954). Lancet, 1, 883.

Stengel, E., and Mayer-Gross, W. (1945). J. ment. Sci., 91, 311.

Thorner, M. W. (1935). J. nerv. ment. Dis., 81, 161.

Trotter, P. A. (1953). Dent. Practit., 3, 376.

(1954). Lancet, 2, 1302.

Tükel, K., and Tükel, M. (1952). Electroenceph. clin. Neurophysiol., $\widetilde{N}$ Wikler, A. (1952a). Fed. Poc., 11, 647.

(1952b). Amer. J. Psychiat., 108, 590.

Williams, R. L. (1954). Electroenceph. clin. Neurophysiol., 6, 497.

Wolf, H. G., and Curran, D. (1935). Arch. Neurol. Psychiat. (Chicago), 33, 1175. 